\title{
Cognitive behaviour therapy reduced relapses in recurrent major depressive disorder
}

Fava GA, Ruini C, Rafanelli C, et al. Six-year outcome of cognitive behavior therapy for prevention of recurrent depression. Am J Psychiatry 2004;161:1872-6.

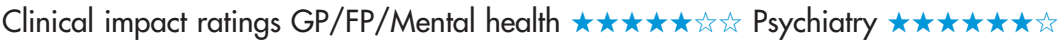

In patients with recurrent major depression who have been successfully treated with antidepressant drugs, is cognitive behaviour therapy (CBT) more effective than clinical management (CM) for preventing depression relapses?

\section{METHODS}

L

Design: randomised controlled trial

Allocation: $\left\{\right.$ concealed $\left.{ }^{*}\right\}$

Blinding: blinded (outcome assessor).*

$\sum\langle$

Follow up period: 6 years

Setting: Affective Disorders Program of the University of

Bologna, Bologna, Italy.

Patients: 45 patients with a current diagnosis of major depressive disorder who were having their third or subsequent episode of depression, with the immediately preceding episode being $\leqslant 2.5$ years before onset of the present episode; reported $\geqslant 10$ week remission between the index episode and the immediately preceding episode; had global severity score $\geqslant 7$ for the current episode; and had had a successful response to antidepressant drugs. Exclusion criteria included a history of manic, hypomanic, or cyclothymic features; and active drug or alcohol abuse, dependence, or personality disorder.

$\mathbf{R}_{\mathbf{X}}$

Intervention: ten 30 minute sessions once every other week of pharmacotherapy plus CBT $(n=23)$ or pharmacotherapy plus $C M(n=22)$. Antidepressant drugs were tapered off at a rate of $25 \mathrm{mg}$ amitriptyline or its equivalent every other week followed by complete withdrawal. CBT comprised treatment of residual symptoms of major depression, lifestyle modification, and wellbeing therapy.

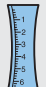

Outcomes: depression relapse assessed every 3 months for 2 years, then every 6 months for 4 years by a clinical psychologist.

Patient follow up: $89 \%$ \{mean age $47 \mathrm{y}, 60 \%$ women\}t.

*See glossary.

†Information provided by author. For correspondence: Dr G A Fava, University of Bologna, Bologna, Italy. giovanniandrea.fava@unibo.it

Sources of funding: The Mental Health Evaluation Project and the Ministero dell'Università e della Ricerca Scientifica e Technologica.

\section{MAIN RESULTS}

Fewer patients in the CBT group than in the CM group had $\geqslant 1$ relapse (table). Furthermore, mean time without a relapse was greater in the CBT group than in the CM group (difference $140 \mathrm{wks}$, $95 \%$ CI 74 to $205, \mathrm{p}<0.001)$.

\section{CONCLUSION}

In patients with recurrent major depression who have been successfully treated with antidepressant drugs, cognitive behaviour therapy was more effective than clinical management for preventing depression relapses.

Commentary

ost randomised controlled trials of treatment for depression stop at 6 weeks, so with 6 years of follow up, the study by Fava et al is a considerable achievement. The authors pick up the story where an earlier report ends. ${ }^{1}$ The earlier article described the same sample after 2 years, and showed a relapse rate of $25 \%$ in the CBT group compared with $80 \%$ in the CM group. The remarkable results of the present article are that this low relapse rate in the CBT group is maintained over another 4 years with the respective relapse rates changing to $40 \%$ and $90 \%$. Expressed as a number needed to treat of 2 this makes CBT a powerful intervention; especially so, given that all participants had previously had $\geqslant 3$ episodes of depression.

However, some obvious problems in generalising the results of this study to clinical practice exist. Firstly, the sample size is small, and the investigators modestly refer to the results as "preliminary." Secondly, the patients appear to have been remarkably cooperative with the research because complete follow up was achieved over 6 years. Complete follow up is something we should celebrate, but I suspect that most clinicians do not achieve such good engagement and follow up in their day to day practice, raising concerns about the generalisability of the participants. Finally, the intervention was provided by a single psychiatrist, with considerable experience of providing CBT. This leads to the problem ever present in psychotherapy trials: Dr Fava is clearly a giffed therapist, but can his results be generalised?

Matthew Hotopf, MBBS, PhD Institute of Psychiatry

Weston Education Centre London, UK

1 Fava GA, Rafanelli C, Grandi S, et al. Prevention of recurrent depression with cognitive behavioral therapy: preliminary findings. Arch Gen Psychiatry 1998;55:816-20.

Cognitive behaviour therapy $(C B T) v$ clinical management $(C M)$ in recurrent major depression after successful treatment with antidepressant drugs*

\begin{tabular}{lllll}
\hline Outcome at 6 years & CBT & CM & RRR (95\% Cl) & NNT (CI) \\
\hline Patients who had $\geqslant 1$ relapse & $40 \%$ & $90 \%$ & $56 \%$ (28 to 76$)$ & 2 (2 to 5$)$ \\
\hline
\end{tabular}

*Abbreviations defined in glossary; RRR, NNT, and Cl calculated from data in article. 